\title{
O USO DA ARGILA ESMECTITA NA CLARIFICAÇÃO DO ÓLEO DE BABAÇU
}

\author{
Antonio Gilson Mendes de Souza ${ }^{1}$ \\ Maron Stanley Silva Oliveira Gomes ${ }^{2}$ \\ Sirlane Aparecida Abreu Santana ${ }^{3}$ \\ Carlos Alberto Lira Júnior ${ }^{4}$
}

Resumo: Dentro das aplicações tecnológicas das argilas destaca-se o seu uso como adsorvente na clarificação dos óleos vegetais. Devido, principalmente, a sua elevada área superficial a esmectita é a variedade mais utilizada. A clarificação ou branqueamento é uma das etapas mais importante para a indústria de refino de óleos comestíveis. Através do processo de ativação, utilizando-se um ácido inorgânico forte $\mathrm{O}_{2} \mathrm{SO}_{4}$, conseguiu-se a melhoria da capacidade sorpotivas do material argiloso. Os parâmetros que medem a qualidade do óleo foram determinados, antes e após o seu contato com a argila no seu estado natural, bem como, após o tratamento com o ácido, e os resultados evidenciaram que houve uma eficiente purificação, além da diminuição da tonalidade escura.

Palavras-chave: Argila; Óleo de babaçu; Clarificação.

\footnotetext{
1 Licenciando em Química/IFMA, Brasil. E-mail: mendes.antonioq@gmail.com.

2 Professor do Departamento de Ensino Superior e Tecnologia/IFMA, Brasil. E-mail: maron@ifma.edu.br.

3 Professora do Departamento de Química/UFMA, Brasil. E-mail: saa.santana@ufma.br.

${ }^{4}$ Professor do Departamento de Ensino Superior e Tecnologia/IFMA, Brasil. E-mail: carlos.lira@ifma.edu.br.
} 